\title{
Voltage and Frequency control in Wind Turbine Using Sparse Matrix Converter
}

\author{
R. Selvamanikandan, P. Usharani
}

\begin{abstract}
Due to the sudden exploitation of conventional resources such as fuel impart to the increase in necessity of power generation through renewable energy resources. So, extraction of energy from wind at a quantity became a well known industry. In this described system, variable-speed wind power generation system using Permanent Magnet Synchronous Generator (PMSG). In PMSG, required voltage induced is not enough to synchronize with the system at lower speed of wind. Also the variations in the wind speed causes the system become oscillatory. In case of maintaining the system stable, Sparse Matrix Converter (SMC) is used. The real time application of large capacity at variable speed providing system by the Pulse Width Modulation (PWM) technique. Because, it can use the vector control and realize torque control. In this analysis, the voltage and the frequency of the given system are taken into account. Simulation output explains the steadiness of the proposed system to maintain the voltage and frequency when desegregated to PMSG wind turbine using Sparse Matrix Converter.
\end{abstract}

Keywords: Doubly fed induction generators (DFIGs, Sparse Matrix Converter (SMC).

\section{INTRODUCTION}

The wind power generation technology has increased as the most important source of electrical energy and is competitive economically with the other sources. Wind energy had been utilized from the olden days in ships sailing, pumping water and grinding grain. The extractable energy of wind is maximum from below100m layer of air has been calculated in the about 1012 $\mathrm{kWh}$ in year. So the available of wind energy in atmosphere is surplus in atmosphere. Our main objective is to convert this energy into electrical in most economical way.

In windmill system, the commonly used generator is induction generator. These generators commonly used in the conversion of wind energy into electrical power. But in case of these machines, the performance of the machine is low. Because of the magnetizing current is zero in the stator current, its efficiency is high compare to the induction generator. And self excitation is the important merits of the synchronous generator which provides operation at high power factor and high efficiency. The synchronous generator is also highly preferred for the full voltage application and generator application.

Revised Manuscript Received on November 22, 2019.

* Correspondence Author

R.Selvamanikandan, Assistant professor in Electrical and Electronics engineeringDepartment, St.Joseph College of Engineering, Chennai,India selvamanipse@gmail.com

Dr. P.Usha Rani, Professor, EEE Department, R.M.D.E.C, Chennai- 206, Senior Member IEEE, pusharani71@yahoo.com.

In recent development in topologies of power converter, converter act an important role in controlling the magnitude and frequency of the generated voltage and output current especially matrix converter. And also these converters can be used to reducing the DC link components with limitations in frequency ratio. It is also provides the variable frequency and variable and reduces the harmonics in supply current.

This model proposes the controlling of parameters such as frequency and voltage by using the Sparse Matrix converters. The entire concept of the network consists of wind turbine, main circuit; power system network and sparse matrix controller are analyzed to examine the described model. In the simulation results, it is explains that the described system network has the surplus efficiency as generation of wind power systems at variable speed. But in much analysis, dc link capacitor considers as demerits that are heavy and bulky; the cost is increases and decreases the overall lifespan of the system. As a substitute of conventional back to back rectifier- inverter, sparse matrix converters modeled during this analysis. The major advantages of matrix converter especially sparse are inherently bidirectional power flow, input output waveforms in sinusoidal with moderate switching frequency, possibility of compact design. From the analysis with conventional converter, it has advantages such as regeneration capacity, operation with unity power factor, sinusoidal input and output.

By the above analysis of the conversion system, this proposal is divided into following sections. Section 1 explains the schematic diagram of the system using Sparse Matrix Converter. Section 2 explains the working of the described model with Sparse Matrix converter. Section 3 explains the simulation output of described model with Sparse Matrix converter

\section{BLOCK DIAGRAM EXPLANATION}

\section{A. Power obtained from wind}

Wind power converts the kinetic energy of the wind blade which is produced by the flow of air into electrical power by the help of wind turbines. To produce large quantities of electricity, a set of turbines are connected to the transmission network in the same place at high voltage is known as wind farm. In China, Gansu wind farm is the wind farm with the capacity of 6000MW in the world. The price of erection and installation of wind power may be huge but there is no fuel cost and it does not need much cost in operating and maintenance when compared to other power plant.

On comparing with the impacts on environment of fossil fuels, wind power is minor and it is more eco-friendly. 


\section{BLOCK DIAGRAM DESCRIPTION}

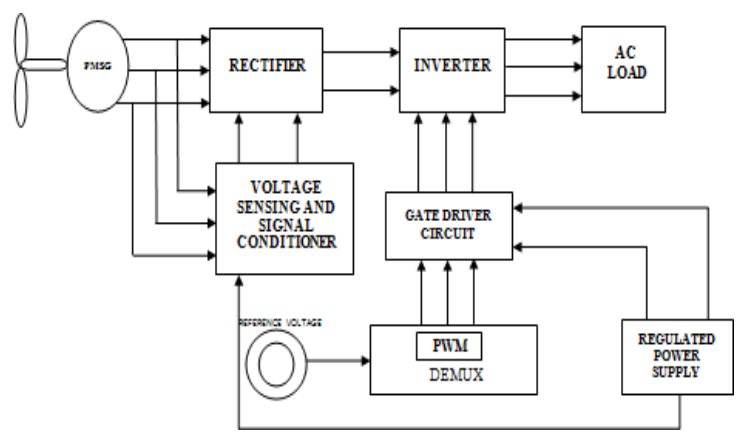

Fig. 1 Block Diagram

\section{A. Wind Power}

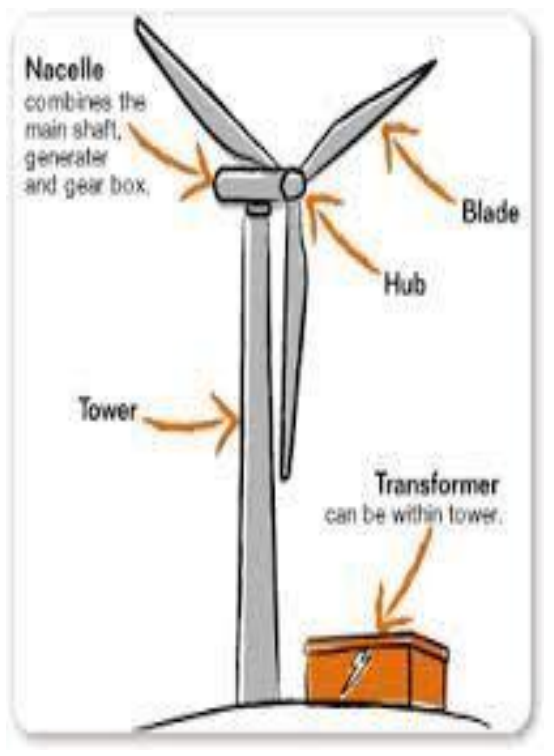

\section{B. Proposed converter (SPARSE MATRIX converter)}

This Converter is one among the Alternating Current to Alternating Current converters. It avoids multi-step commutation procedure and offers reduced complexity modulation scheme because of less number of components and low realization effort. These are the difference between the conventional converter and Sparse Matrix converter.

Figure 3 represent a schematic model of a SPARSE MATRIX converter, consisting Characteristics of this Converter model are 18 Transistor sand 18 Diodes. Instead of the other matrix converter this converter gives identical function, but due to minimum number of power switches and the choice of employing an enhanced scheme provides minimum control of complexity and good safety, reliability.

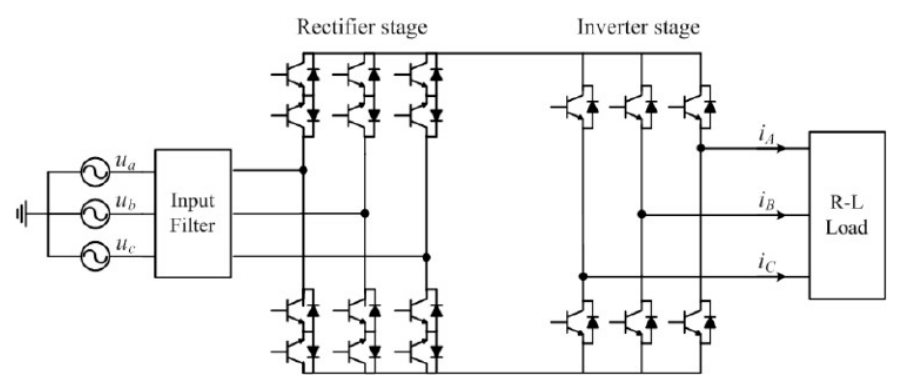

Fig. 3 Described Converter model

\section{Rectifier Stage Control}

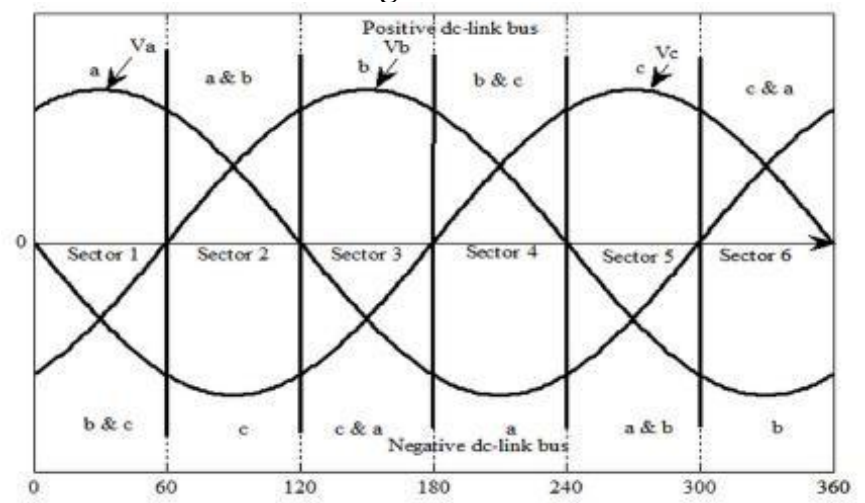

Fig. 4 Modulation strategy of Rectifier stage

The above figure explains the modulation strategy of the rectifier stage in the SMC. From the phase angle with the deviation of degree 60, a complete cycle is classified into six sections. Consider the waveform of three phase voltage. Each phase is represented by $a, b$ and c. From the region of 0 degree to 60 degree, positive cycle is a phase while in negative cycle is b and c. Then M2, M6 are become ON state and remaining switches in the rectifier stage are become OFF state. Similarly, the sector switches accordingly.

\section{Inverter Stage Control}

In sampling, the difference between the value is referred and valve obtain is taken into account. If the valve is positive, then it will be in ON state otherwise in OFF state.

\section{E. Synchronous Generator (Permanent Magnet)}

This Generator is a generator in which external DC source is not required for the excitation since it is given by the permanent magnet. In this generator, rotor consists of magnet which is permanent and stator consists of stationary armature that is connected to electrically load. Here, the field is produced by the magnet mounted to the shaft and current induced in the armature so rotor and field operate with the same speed. Thus it has the term synchronous.

\section{F. Modulation Technique}

The other name of this technique is also known as Pulse Duration Modulation (PDM). By utilizing the digital source, analog signal can be produced in PWM technique. Moreover, it describes the characteristics of the waveform by two main components i.e., duty cycle and frequency. In short, it encodes message into required pulsing signal.

\section{WORKING OF BLOCK DIAGRAM}

In this system, Synchronous Generator can be act as generator and also connected to the turbine. The voltage is noted and continued by the block. The output is input to the rectifier. This rectifier section consists of six numbers of switches. The switching is based on three phase voltage obtained and divided into switching states of nine modes. 
Here, the ac output voltage is converted into dc. Filter is used to minimizing the distortion in the outcomes of the rectifier. The voltage referred from the grid is given into inverter controller circuit. This pulse signal is fed to input of the inverter through Driver Circuit.

\section{SIMULATION RESULTS}

Proposed simulation diagram

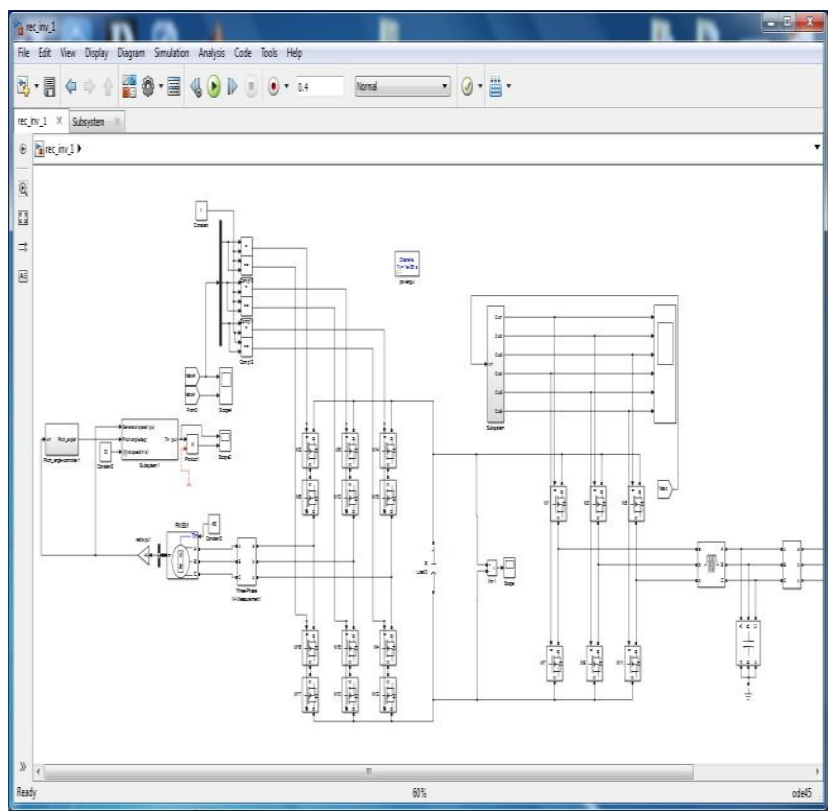

Fig. 5 Simulation Diagram

Fig 5 represents the simulation diagram for controlling frequency and voltage and the simulation output of the described method is analyzed by the help of MATLAB software. Simulation is explained below for described method.

\section{1) Input Pulse To Rectifier}

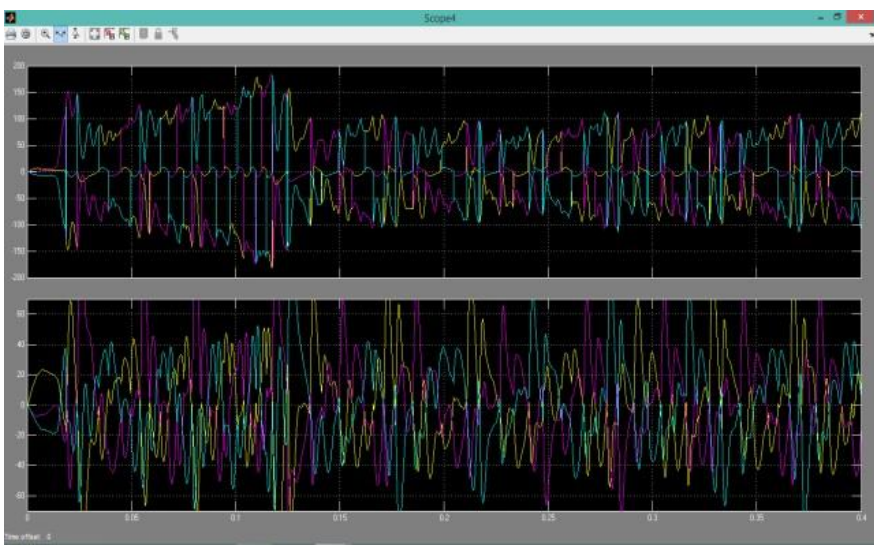

Fig. 6 Switching Pulse to rectifier

Fig 6 represents the AC signal from the PMSG whose frequency and voltage is variable since the wind turbine rotates with respect to variable speed of the wind and this is fed as the input to the rectifier side of the Converter which is sparse matrix.

\section{Waveform of Voltage and Current output}

The described system voltage and current of the output waveform is as shown below in the fig. 7. It is clearly explains that the output voltage and current becomes constant due to the SMC.

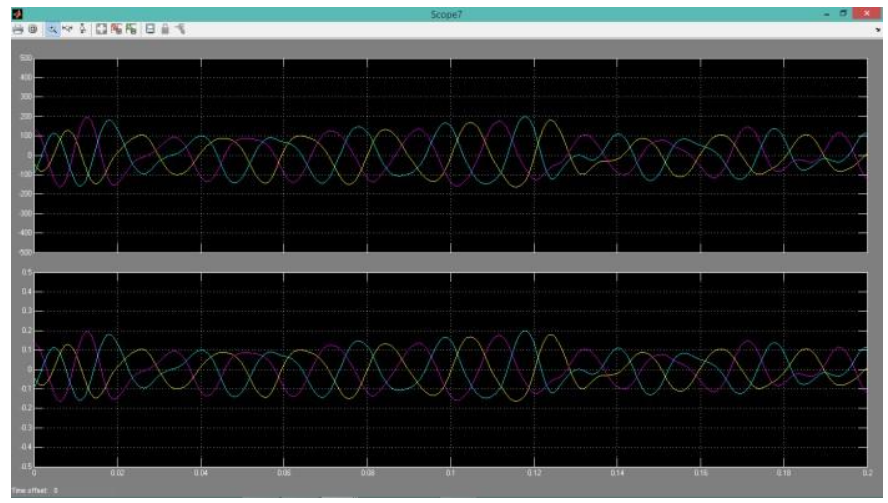

Fig.7 Voltage and current output waveform

\section{CONCLUSION}

The aim of above analysis was to explain the consistency of the described model to maintain the voltage and frequency when desegregated to wind turbine based on Matrix Converter. By the difference in the wind speed, the voltage generated and frequency is kept same with the implementation of SMC and also reduced the generated harmonic when compared to existing structure.

\section{REFERENCE}

1. Bahman Khaki,Mohammad Iman Bahari, S. Ebrahim Afjei, "DFIG Wind Turbines with Very Sparse and Sparse Matrix Converters to control frequency" 8th Power Electronics, Drive Systems \& Technologies Conference (PEDSTC 2017)14-16 Feb. 2017, Ferdowsi University of Mashhad, Mashhad, Iran.

2. Mohamed Aner, Edwin Nowicki, David

Wood," Employing a Very Sparse Matrix Converter for Improved Dynamics of Grid-Connected Variable Speed Small Wind Turbines"

3. L. Huber, D. Borojevic, "Space vector modulated three- phase to three phase matrix converter with input power factor correction", IEEE Transactions on Industry Applications (Volume:31, Issue: 6 ). Pages 1234-1246, Nov. 1995.

4. D. Casadei, G. Serra , A. Tani, L. Zarr, " Matrix converter modulation strategies: a new general approach based on space- vector representation of the switch state", IEEE Transactions on Industrial Electronics (Volume:49, Issue: 2 ), pages 370- 381, Apr. 2002.

5. Alesina; M. G. B. Venturini, "Analysis and design of optimum amplitude nine-switch direct AC-AC converters", IEEE Transactions on Power Electronics, pages 101-112, 1089.

6. K. B. Larsen, A. H. Jorgensen, L. Helle, F. Blaabjerg, "Analysis of symmetrical pulse width modulation strategies for matrix converters", Power Electronics Specialists Conference, 2002. pesc 02. 2002 IEEE 33rd Annual, pages:899 - 904 vol.2, 899 - 904 vol.2.

7. Vadillo, Javier, J. M. Echeverria, Miguel Martinez-Iturralde, and Luis Fontan "Modelling and simulation of indirect space vector modulated matrix converter using MATLAB®/Simulink®." International Journal of Electronics 96, no. 8 (2009): 855-863

8. Malekjamshidi, Zahra, Mohammad Jafari, Dan Xiao, and Jianguo Zhu. "Operation of indirect matrix converters in different SVM switching patterns." In 2015 4th International Conference on Electric Power and Energy Conversion Systems (EPECS), pp. 1-5. IEEE, 2015.

9. S. Tammaruckwattana and K. Ohyama, "Modeling and simulation of permanent magnet synchronous generator wind power generation system using boost converter circuit," in Proc. EPE, pp. 1-10, 2013. 


\section{AUTHORS PROFILE}

Mr. R. SELVAMANIKANDAN M.E, is Assistant professor in Electrical and Electronics engineering Department, St.Joseph College of Engineering, Chennai, India. He has completed his M.E in valliammai Engineering College, Anna University, Chennai. He has completed his B.E in Electrical and Electronics engineering in the year 2010 in Annai Mathammal Sheela Engineering College, India

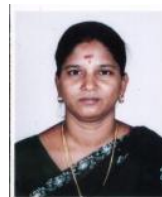

Dr. P. USHA RANI, M.E. Ph.D, is Professor in Department of Electrical and Electronics Engineering, R.M.D Engineering college, Chennai. She completed her B.E (EEE) from Govt. College of Technology in 1991, M.E (Power Systems) from College of Engineering, Anna University in 2002, and Ph.D (Power Electronics \& Drives) from College of Engineering, Anna university in 2011. She has been in the teaching profession for the past 23 years and has handled PG / UG programme and total experience of 27 years. Areas of her interest are Power Electronics, Power Systems, Power Quality and FACTS. She has published 57 papers in International and national Journals / Conferences (IEEE Xplore-7). She has a reviewer for international journals. She is a member of IEEE and ISTE. 